\title{
The Dangers of ICT on Youth Development in Nigeria
}

\author{
Martins C Okoro
}

\begin{abstract}
The term "Internet" seems to be the most popular and fashionable vocabulary in vogue now. No saying it means different things to different people.

Nevertheless, everyone agrees on one point, the internet is complex, fascinating, challenging almost mysterious but beneficial.

Most experts attribute globalization to improvement in information and communication technologies via Internet. Information and communication Technology (ICT) is the most recent technology challenging the traditional process of teaching and learning. Internet is in vogue in the education sector and of course in all sectors of human endeavour where communication needs to be improved.
\end{abstract}

In commerce, we have e-Banking where a customer could pay for goods and services using "POS" (Payment On Sale).

In sports, say football, one could follow a football match minute by minute using www.goal.com

In other entertainments like music, one can easily download any album of his/her choice through the Internet. You can also use the internet to upgrade systems such as Computer Software. Weather forecast could also be done using internet.

Internet has become key tools and had a revolutionary impact on how we set the world and how we live. Therefore, it must be explored and exploited optimally. So parents send their children/wards into this strange mind boggling new world of technology for exploration. What these parents fail to realize is that the Internet can mar these children for life.

This paper attempts to highlight the dangers of the Internet Vis-à-vis youth development.

Index Terms - ICT, Internet, youth, development.

\section{INTRODUCTION}

It will be stating the obvious here to attempt to highlight the relevance of ICT (Information and Communication Technology). Some people already see the world as a global village, thanks to ICT. To begin with, it saves time, cost energy and space. However ICT needs to be properly channeled to arrive at desired or desirable goals. In fact Egbokhare, F. O. (2006) quoting the United Nations Secretary Kofi Annan says that a technological revolution is transforming society in a profound way. If harnessed and directed properly ICTs, according to Annan, have a potential to improve all aspects of our social, economic and cultural life. We can say by extension, that if ICTs are not harnessed and directed properly, they also have potential to destroy all facets of society.

Martins C Okoro is with Federal College of Education, Enugu State Nigeria engrokoro@gmail.com, +2348038340026.
When we talk about society, we are talking about people. ICT has continued to change society at an unprecedented rate and has provoked an unprecedented integration of the global society. Millions and millions of computer users hook up to the Internet every day. Some people have tried to figure out who all those users are. The internet therefore has spread in use and acceptance faster than the other technology the world has known and lends itself readily to teaching and learning (Udoada, M. P. 2006).

Learning and teaching, per se, are good concepts. They aim at transforming the individual. However, the materials being taught and learnt, the timing, the environment, plus other factors determine whether the transformation will ultimately, be constructive or destructive. It is not the purpose of this paper to condemn the Internet in its entirety. This paper rather seeks to discuss the destructive and negative effects of learning through the Internet on the youths of today. The paper also discusses the challenges, facing parents in minimizing these undesirable effects. It also concludes with some suggestions that may help youths benefit from the Internet without destroying their future.

\section{THE INTERNET - WHAT IS IT ALL ABOUT?}

Szyperski, C. et al (2002:499) define the Internet as "a network connecting computers all over the globe.

\section{A BRIEF HISTORY OF THE INTERNET IN NIGERIA}

A lot of people, enlightened ones inclusive, do not quite know when or how the Internet came into existence. It seems as if the Internet sprang up overnight. That, according to Capron (1997:196) is not true. He says:

The history of the internet bears telling. It is mercifully short.

The reason...is that it is slumbered and stuttered for approximately 25 years before the general public even knew it existed. The 'Net was started by obscure military and university people as a vehicle for their own purposes. They never in their wildest dreams thought it would become the international giant it is today.

The Internet started life as ARPANET (Advanced Research Project Agency Network) in 1969. The original motive of the ARPANET which was initiated by the United States was to build a network capable of carrying military government information from one point to another during the nuclear war. (Szyperski, et al-2001; Capron, H. L. - 1997); Orimalade, J. A - 1999). Ever since the general public became aware of the 
existence of the Internet, the phenomenon has spread like wildfire across the globe. Capron attributes this growth rate to four factors namely: The Universal TCP/IP standard, the web-like ability to link from site to site, the ease of use provided by the browser's graphical interface and lastly, the growth of personal computers and their local area networks that could be connected to the Internet.

\section{THE DANGER OF THE INTERNET TO NIGRIAN YOUTHS}

Agreed, the benefits of the Internet cannot be overestimated. But then its danger cannot also be underestimated. Here, we are going to examine some of the facilities/packages on the Internet that are detrimental to youth development if not carefully harnessed. We shall do this on different platforms beginning with the platform of religion.

\section{DANGERS TO REligious DEVELOPMENT}

In this section we focus our attention on occult, most especially what is called the "New Age Movement" (NAM). The term occult means "that which is hidden or secret". The phenomenon, "New Age", on its part connotes a new paradigm, a new attidue to life. According to Okon, B and Abonyi, I (1997):

This new way of looking at thing is closely related to be esoteric and the occult as a utopia so vast that one can find in it a satisfaction for his or her religious aspirations. The adepts of this movement designated it as the "Golden Age" and "the Age of Aquarius"

The range, scope and influence of the NAM is worldwide, Okon and Abonyi trace the origin of NAM to the following: Occultism, Freemasonry, Theosophical societies, Secular Humanism, and Syncretic movements. According to Cumbey, C. (1983) organizations like the Amnesty International, Green Peace, the Sierra Club, children of God, Zero population growth etc, openly and proudly call themselves "New Age Movements." These organizations have achieved "energy" through a process of networking called "Segmented Polycentric Integrated Network" (SPIN) (Ferguson M (1980). Other groups include World Goodwill, Arcane School, Triangles, People for the American Way, New Group of World Servers. The NAM has several books on which they base their doctrine. The major ones among these anti-Christian literatures are the "Aquarian Gospel of Jesus Christ" and the Satanic Bible". Okon \& Abonyi again comment on this:

It is very clear that all those books and doctrines are directly antithetical to Christian doctrine as found in the scared scriptures. This is the NAM's attempt at replacing Christian scripture with satanic ones for the "Age of Aquarius" come AD 2000

Okon and Abonyi further identify several other arms of the NAM bearing harmless and respectable names like the SIECUS (Sex Information and Education Council), the Satanic Church in California (founded by Anton Lavey), the Lucis
Trust, Planetary Initiation for the World we Choose, Unity in Diversity, the Sutphen corporation. People should be conscious of them and avoid them. The NAM uses them to recruit people and initiate them to become members. These bodies jointly write books which are published by the Lucifer Publication Company founded by them. Thus we see how those ancient ills of paradigm are now freely preached by the NAM through organizations which have adopted new names to deceive and capture the unwary.

One may ask what has all this to do with our subject matter the Internet. We need no oracle to tell us that all these organizations mentioned (which started networking long before the general public heard the word Internet) have websites through which they disseminate their message. Here the E-mail does a lot of damage. As Capron says;

The E-mail can be a dangerous time bomb because...

more than any other kind of written communication, the E-mail reflects the real unedited thoughts of the writer.

Thus the E-mail constitutes one of the major channels of dissemination of the NAM because it is very cheap: hear what Capron says about Junk E-Mail:

A postal mailing to a million people costs about $\$ 800,000$.

Internet marketers can reach the same number of people by making a phone call and paying a few hundred dollars for time spent online.

The software that makes mass advertising - called "spamming"- possible both gathers E-mail addresses and sends E-mail messages for marketers - thousands and thousands every day.

Apart from the E-mail other dangerous facilities are "Newsgroup" and Chat box". Newsgroup discussion covers almost any subject one would imagine. If a user is contemplating joining a secret cult, for example, the Newsgroup specializing on cultism is there to offer free information on which ones are best (or worst). They even give the number of websites having more information on this and can even show graphics of initiation ceremonies. The group tells the interested user what lies to tell parents to allay their suspicious. This is evident in the increasing menace of occultism in our institutions of higher learning. These occultic groups are either direct arms or subsidiaries of the NAM. The renewed atheism and paganism promoted by these cults is part of the triumph of the New Ages (Okon and Abonyi, 1997)

As we all know, youth like to experiment. Anything new and sophisticated attracts them. The Internet fascinates them. So through regular browsing and perchance, serendipity, youths come in contact with these unwholesome groups who sell them false theology. Capron clearly points this out. He says:

The Internet is full of misinformation. Just because something is on the Internet does not mean it is true... if you are doing serious research on the Internet, be sure to back it up with other sources.

The NAM, according to Okon \& Abonyi (1997) is one of 
those false movements which has come in disguise as the preacher of the apocalyptic Jesus and have enslaved many people. They advise the Church in Nigeria not to delude itself that this movement has not reached the Black Continent. According to them the activities of the NAM are already present through bodies like the Grail Message, the Rosicrucian, the Eckankar and the noiseless enemies on our campuses called secret cults.

\section{DANGers to Moral DeVElopment}

The danger of the Internet lies primarily in the World Wide Web (WWW). The WWW as Heatcote, P. M. (2002;32) put it, is a special part of the Internet which allows people to view information stored in participating computers. It is an easy-to-use graphical source of information which has opened the Internet to millions of people interested in finding out information of any kind. It represents the largest collection of materials accessible almost anytime anywhere by almost anyone having a browser. Infact, Singhal (1997), calls the WWW a virtual library at one's fingertips. One of the attractions of the web is the case of using search engine to communicate. A search engine is software that narrows down the search for any required information. It lets the users specify search terms and the search engine finds sites that fit those terms.

The summation of the advantages of ICTs, the Internet inclusive is communication. For communication to be effective in achieving the objectives of forging men and races together, participants in the communicative event must be prepared to employ the tactics of verbal give-and-take (Ajiboye, T. 2003). Given the context we are dealing with in this paper, it is doubtful if the youth have anything to give. They, certainly, have something to take home-trash. One may wonder how.

A visit to any one of the cybercafés springing up daily reveals rooms of varying dimensions stocked with computers. Seated before these computers will be youths, mainly boys, their eyes glued to the screens. Sometimes four or more such youths share a computer. What materials are on those screens? Pornography. There is no need to wonder how they arrived at such sites, with the bulk of materials available on the "Net". The search engine narrows down the search. All one needs do is submit the one word you are interested in. Web pages provide access to many source of information. And as Capron (1997) states, a simple one word search will yield many sites having information on the particular word. So if a word "sex" is submitted, the user gets access to sites showing literatures and graphical representations of orgies, aphrodisiacs, homosexuality, pedophilia and all sorts of sexual perversions.

As Udoada (2006) submits that literatures arouse emotions in a heightened form. Naturally these aroused youths will look for outlets to release tensions built up by this communication process.

Another potent facility is the electronic mail. The E-mail allows text, sound and video to be sent to others. It is common practice nowadays among youngsters to send pornographic videos and texts to their peers especially those they consider to be prudish. Parents sponsor their wards to undergo computer training at cybercafés. Here, these naïve and innocent youngsters watch other youths surfing the Net (mostly for pornographic stuff). They become very interested and learn fast in order to be able to delve, unsupervised, into these sites offering unabashed, raw information and picture about those forbidden, whispered - about areas of life called sex. The branch of the NAM called SIECUS, which we mentioned earlier, specializes in propagating the concept of self-gratification. This concept promotes Hedonism which teaches that gratification of one's lust and a life of pleasure are the fulfillment of man's destiny on earth. This is why we are witnessing the birth of pro-abortion bodies in Europe and America, clamouring for the legalization of abortion. In fact the activities of the NAM centre mostly on sex and promiscuity as Okon \& Abonyi assert:

They do not see anything wrong with indulging in indiscriminate sexual intercourse. They call it "fun" This is found expressed in paid advertisements (like those of condoms and GSM companies), films Artistic works, drama etc (all these are available on the Internet) following this... Is the high rate of drugs abuse, rape and murder... The production of many drugs are being sponsored by the NAM and these are responsible for the staggering increase in crime...their side effects are really driving men and women crazy and winning souls for satan, the revered master of the new Agers.

On the Chat box and Newsgroups youth come in speaking contact with the propagandists who deceive, indoctrinate and even hypnotize them. These promoters show the poor youth how to sniff, inhale and smoke hard drugs. Graphics of drug users are sent to them through e-mail to show these drugs. They are also advised on what brand of condoms and contraceptive pills to use. In fact NAM bodies distributes cartons of condoms to third world countries in the guise of their contributions towards fighting HIV/AIDS.

\section{DANGERS TO ACADEMIC/INTELLECTUAL DEVELOPMENT}

Some people have been working wondering who the users of the Internet are. Capron (1997:196) answers this question succinctly: Hear him

Some have guessed that it is mostly teenage boys who hang out on the Internet, and that they are there for hours and hours at a time. This partly right There are certainly lots of teenage boys on the Internet and they probably have more time than most of us to surf the 'Net'.

We are of the opinion that it is not really because they have more time but rather because they misappropriate time. Those hours spent at the cybercafé are probably meant for school work. It is common these days to see teenagers in school uniforms at cybercafés in the morning hours browsing. To worsen matters the addictive nature of surfing the 'Net' means these teenagers browse almost on a daily basis to the detriment 
of their academic pursuit.

Being regular in school also helps in the intellectual development of the young ones. Extra-curricular activities like sports, offers a healthy outlet for excess energy in youths. They also develop in the young ones the spirit of good sportsmanship and general mental development. Nowadays, teenagers would rather be found on the 'Net rather than on the field. On the 'Net" they develop base instincts, base and corrupt minds became of the base and corrupt materials the internet feeds them with.

The craze of the Nigerian youth and even a portion of the adult population for the English Premier League and other Leagues across the world is a disturbing development. So is the inexorable addiction of the people to facebook, twitter, yahoo messengers and other social interaction mechanisms including facility such as YouTube on the Internet. All these undoubtedly have obvious benefits, but addiction to them disproportionately claims gargantuan amount of time relative to their probable utilitarian value. Before the ICT revolutions, leisure time, especially by students, were devoted to reading literature of diverse kinds including English Classics like works of Shakespeare, Charles Dickens, Geofrey Chaucer et al. Ironically, there are greater opportunities for extensive learning today than there ever had been, given the incredible amount of information on the Internet, but alas, majority of users occupy themselves with vain and inconsequential engagements. The insidious fact of the Premiership-mania may appear an innocuous pastime, there is, however, no gain saying the fact that time is a valuable resource that ought to be wisely invested. There is average of 10 matches in the English Premier League every week, this is not to talk of the Spanish La Liga, the German's Bundesliga, the Italian Series " $A$ " and the UEFA fixtures. All of these are watched beamed live on satellite televisions and watched en mass with monomaniac passion. One wonders why people are devoting a considerable amount of scarce resources like time on leisurely engagements with no observable salutary impact on their lives. Apart from the direct issue of money paid to watch the matches which would not stay in Nigeria but ultimately go to the pockets of foreign clubs and the satellite televisions providers, the opportunity cost of the enormous productive hours wasted and which would have been better invested in genuine profitable ventures constitutes another cause for concern. Not the least because the Premiership is not a one-off thing but a continuum. More bizarrely, we have heard for example, stories of some young Nigerians who maimed or killed one another in scuffles engendered by bitter alterations flowing from idiotic arguments on questions such as, which is the greater clubs between Arsenal or Manchester Utd? Or whether or not Chelsea has better players than Barcelona Utd or on a question such as who is a better tactical wizard among Alex Fergusson, Josse Mourinho, Arsene Wenger, and David Moyes? Sheer arrant nonsense! If the audit of the amount of resources Nigeria is losing by these seemingly innocuous but costly inordinate engagements of the people with the Premiership, Facebook, twitter, yahoo messenger and YouTube is undertaken, the cost are sure to be staggering. But that is not all, what about the pornographic websites which the youth ( and some adult too!) often frequent and the violence-prone, debased films suffusing the internet and constituting evergreen lures to young and impressionable people. All these are moral toxic waste imported from abroad via the instrumentality of the ICT which undermine the norms and values of our society.

\section{DANGER TO HEALTh}

Long exposure to rays emitted by computer screens is dangerous to health. This is why some business outfits attach special protective screens to their computers to shield their employees especially secretaries from direct emissions. We are yet to see cybercafés that attach any such screens to their systems for obvious reasons. Some youngsters begin to browse right from the primary school. By the time these same youths browse regularly and for long hours on the and end up to the university level, one can but imagine what latent health hazard they will experience in life.

Again, through Newsgroups, Chat box, blogs etc youths come across health products. Youths are curious. They see everything as pranks. What happens if some of their health products are not really meant for what the speakers on the "Net" claim? What if they take an overdose? Capron offers a suggestion. Hear him:

A suggested rule is that you observe the newsgroup for a while, an activity called 'lurking", before you jump in......another rule is to skip participating in a group you do not accept their underlying premise.

For example, an aetheist should not join newsgroup of priests discussing canonical matters... Just go away This is just it. 'Just go away!'.

\section{Control}

There is a standardization body associated with the internet. This body called IETF (Internet/Engineering Task Force) is an umbrella covering standards. Its function is to look after the bulk of the standard enabling the operation of the Internet. These standard include TCP (Transport Control Protocol), IP (Internet Package), HTTP (Hypertext Transfer Protocol), SNMP (Simple Network Management Protocol). We should never delude ourselves into believing that the standards here have anything to do with the quality or veracity or materials entering the "Net". The TCP/IP, for example, are concerned with transportation and delivery of packets. Actually no-one is out there to monitor the quality or veracity of stuff glutting the internet. In fact Capron, talking about newsgroup/chat box submits:

A more insidious problem possibly awaits those who participate in unsavory groups....parents are concerned about "adult" forums that may be accessed by minors. Newsgroups are among the oldest and most cherished institutions on the Internet. They were around long before the mass participation 
of users in the Web and will continue to reveal in their own special subject matters.

So these standard bodies mentioned are not like the Nigerian Film Censor Board. Anybody who can afford the price of a Web site is free to market whatever stuff he desires.

\section{Suggestions}

Before the advent of the Internet, peer group problems could be controlled by parents. But how can parents control, the quality of materials available on the Net? Parents should have heart to heart talks with their kids about the unwholesome things they might find on the Internet. The slogan should be "Just go away" if you tumble on such site.

Parents should also visit their children's schools to find out how regular they are at school. In fact, a better option is to exchange phone numbers with their class teachers, without the children's knowledge, with the instruction to report when such children are absent or late in school. Parents should try, if possible to develop friendship with the personnel of cybercafés to which their children undergo training and appeal for their monitoring.

Finally, parents should also be more fervent in praying for their children. They should also show them good examples by practicing what they preach to their children because as Capron concludes:

The internet has been heaped with well deserved praise. But still there are concerns. To begin with, no one really knows exactly who is out there on the "Net" and what they are doing online. It's a little worrisome. On the other hand, many users find the freewheeling, no-controls aspect of the internet appealing. Many fear government attempts such as the Telecommunication Bill of 1996, which proposed fine and jail term for offenders to tame the internet operators.

Although this bill was struck down by the courts, the issues remain.

\section{CONCLUSION}

This paper, certainly, did not set out to malign the internet. It only attempted to point out how it can destroy our society if mishandled. The youths of today make up the worlds society of future generations. If they are mal-formed, then a mal-formed society is in the incubator. We see our youths sporting weird hair styles, weird clothes, weird mannerism, they carry occult books/magazines around, kiss and fondle each other on the streets in broad daylight and generally have a new outlook about everything. Our youth certainly need some comprehensive value-laden reorientation on how to make modern inventions our allies rather than a burden.These hairdos etc, they see on the Internet. Since there are many other wholesome materials on the Net, we should encourage our youths to direct their interest towards this direction.

\section{REFERENCES}

[1] Ajiboye, T. (2003), "Coping with Global Integration: The Place of Communication" in JONIFOEL, vol. 1, No 3, pp 2-7

[2] Capron, H. L. (1997) "Computers: Tools for an Information Age" (5th Edition) Massachusetts, Addition - Wesley, Longman Publication Company

[3] Cumbey, C. (1983). " The Hidden Dangers of the Rainbow", Lousiana, Huntington Inc.

[4] Egbokhare, F. O. (2006) "Language and Technology Interface: Creating Opportunities for Indigenous Language and People" In COE Ikere, School of Languages Book of Proceedings, pp 1-3

[5] Ferguson, M. (1980)," The Aquarian Conspiracy", Los Angeles, J. P. Tarcher Inc

[6] Heathcote, P. M (2002) “A” Level ICT (2nd Edition) West Midlands, W. M. Print Ltd

[7] Okon, B. \& Abonyi I (1997), "The New Age Movement: its Impact on the Catholic Church" In NACATHS, Vol. 7 March 1997, pp 46 - 59

[8] Orimalade, J. A. (1999), "College Computers Science" (2nd edition), Lagos Data Analysis and Processing Services

[9] Szyperski, C. et al (2002) "Component Software" (2nd Edition) New York, Addison Wesley

[10] Udoada, M. P. (2006), "Teaching English as a 2nd Language through the Internet in Nigeria" In COE, Ikere, School of language Books of Proceedings, pp 13-137 